Georgia State University

ScholarWorks @ Georgia State University

$2-11-2021$

\title{
Balancing race, gender, and responsibility: Conversations with four black women in educational leadership in the United States of America
}

Natasha Johnson

Georgia State University, njohnson93@gsu.edu

Follow this and additional works at: https://scholarworks.gsu.edu/cj_facpub

Part of the Criminology and Criminal Justice Commons, and the Educational Leadership Commons

\section{Recommended Citation}

Johnson NN. Balancing race, gender, and responsibility: Conversations with four black women in educational leadership in the United States of America. Educational Management Administration \& Leadership. February 2021. doi:10.1177/1741143221991839

This Article is brought to you for free and open access by the Department of Criminal Justice and Criminology at ScholarWorks @ Georgia State University. It has been accepted for inclusion in CJC Publications by an authorized administrator of ScholarWorks @ Georgia State University. For more information, please contact scholarworks@gsu.edu. 


\begin{abstract}
This paper focuses on equitable leadership and its intersection with related, yet distinct concepts salient to social justice, pertinent to women and minorities in educational leadership. This piece is rooted and framed within the context of the United States of America, and the major concepts include identity, equity, and intersectionality - specific to the race-gender dyad - manifested within the realm of educational leadership. The objective is to examine theory and research in this area and to discuss the role they played in this study of the cultures of four Black women, all senior-level leaders within the realm of K-20 education in the U.S. This work employed the tenets of hermeneutic phenomenology, focusing on the intersecting factors - race and gender, specifically - that impact these women's ability and capability to perform within the educational sector. The utilization of in-depth, timed, semi-structured interviews allowed participants to reflect upon their experiences and perceptions as Black women who have and continue to successfully navigate the highest levels of the educational leadership sphere. Contributors' recounted stories of navigation within spaces in which they are underrepresented revealed the need for more research specific to the intricacies of Black women's leadership journeys in the context of the United States.
\end{abstract}

Key Words: Educational leadership, Black women educational leaders, equity, identity, intersectionality, race-gender intersectionality

This research did not receive any specific grant from funding agencies in the public, commercial, or not-for-profit sectors. 


\section{Balancing Race, Gender, and Responsibility: Conversations with Four Black ${ }^{1}$ Women in Educational Leadership in the United States of America ${ }^{2}$ Introduction}

In the United States of America, women comprise over half of the labor force and currently predominate in mid- to lower-level managerial ranks (Yukl, 2009). Yet, they are only marginally represented at the executive levels (Hill, Miller, Benson, \& Handley, 2016; Rhode, 2017). Despite this reality, women continue to provide a qualified pool of potential leaders (Prime, Carter, \& Welbourne, 2009). Notwithstanding, there is a growing body of scholarship in the U.S., demonstrating that women professionals are well suited for more advanced leadership positions in every sector (Kellerman, Rhode, \& O’Connor, 2007; Sanchez-Hucles \& Davis, 2010). This exclusion, also known as the 'leadership divide', is even more pronounced for women of color (Richardson \& Loubier, 2008). This especially holds true for Black women, in spite of their status as the most qualified group in terms of educational attainment (Davidson \& Burke, 2000; Eagly \& Carli, 2007; Eagly, Eagly, \& Carli, 2007; Rosette, Koval, Ma, \& Livingston, 2016). Nonetheless, they remain, as a collective, at the bottom half of the organizational hierarchy (Bell \& Nkomo, 2001).

This leadership disparity is even more stark within the US educational realm. A present challenge for women in education is that while they reflect roughly 75 percent of the workforce, they represent less than 20 percent of those in senior-level leadership (DeWitt, 2016; Gupton, 2009). In addition, White men and women, as a collective, represent the vast majority of K-20 educators in the United States. According to the U.S. National Center for Education Statistics,

\footnotetext{
${ }^{1}$ For the purposes of this paper, Black = Black/African-American, as all study participants classify as Black/African-American.

${ }^{2}$ Throughout this paper, U.S., United States, United States of America, and America are used interchangeably.
} 
the racial distribution of all full-time faculty in degree-granting postsecondary institutions between Fall 2015-and Spring 2016 was as follows: “41 percent were White males; 35 percent were White females; 6 percent were Asian/Pacific Islander males; 5 percent were Asian/Pacific Islander females; and 3 percent each were Black males, Black females, Hispanic males, and Hispanic females” (US Department of Education, 2016, p. 1). In addition, Hussar et al. (2020) and McFarland et al. (2019), in their iterations of The State of Racial Diversity in the Educator Workforce $^{3}$, found that over 80 percent of public-school educators were White, in comparison to roughly 50 percent of all public-school students in the US. Further, 16 percent of students were Black, as compared to 7 percent of public K-20 educators. This same report found that educational leaders, at large, remain a racially homogenous group, with over 80 percent of public-school administrators classifying as White, 10 percent Black, and 7 percent Hispanic. In recent academic years, the proportion of public-school executives who were White was 82 percent, 11 percent Black, and 5 percent Hispanic.

A necessary step in reducing the leadership gap involves the detection of ineffectual cultures, including those possessing leadership behaviors that do not take the expectations and experiences of all organizational members into account (Hofstede, 2011). The current singletrack leadership archetype, specifically, the prevalence of middle-aged, White male educational leaders in U.S. education large-scale (Allan, 2003; Betters-Reed \& Moore, 1995), reflects this persistently pervasive gap. As such, there is a responsibility on the part of all extant stakeholders to provide and promote equitable, justice-based spaces for all those who do not fit the extant and longstanding leadership stereotypes.

\footnotetext{
${ }^{3}$ See https://nces.ed.gov/programs/digest/d13/tables/dt13_209.10.asp.
} 
Allan (2003), Parker and Villalpando (2007), Sawyer, Salter, and Thoroughgood (2013), and other scholars agree that these existing paradigms cannot be uprooted without transparent conversations about the presence of gender and racial inequities in educational leadership. Given the unique and intersectional experiences of women leaders at-large, and Black women in particular, a multidimensional approach is required to create equitable pathways to leadership. According to Betters-Reed and Moore (1995), progress, in this regard, requires investigating the origins of inequity, the preservation and duplication of imbalanced structures, the social consequences of stratification, and the ever-changing systems of inequality. The theory and research on this topic, however, remain largely underdeveloped, making it difficult to implement "good" policy to address inequities in this capacity. I, therefore, support the need to move away from simply treating the experiences of leaders as homogeneous, and instead, begin to consider leadership as applicable to broader social, cultural, and historical contexts.

Toward that end, this paper highlights the need for relevant stakeholders to better understand the roles of race and gender in educational leadership. Turning our attention to the research in this arena, I begin with an examination of the literature related to the historical representation of women in this sphere. This literature review framed the current study, examining the impacts of gender and race on four Black women's experiences as senior-level educational leaders. The paper highlights the need for more discussions and recommendations for theory advancement, research development, and the implementation of actionable practices, geared towards reducing the noted leadership gaps in U.S.-based education. 


\section{Identity, Race-Gender Intersectionality, and Leadership in "Context"}

\section{The Importance of Identity, The Relevance of Intersectionality in this Context}

The concept, identity, “operating 'under erasure' in the interval between reversal and emergence; [is] an idea which cannot be thought in the old way, but without which certain key questions cannot be thought at all" (Hall \& Du Gay, 1996, p. 2). Hall and Du Gay (1996) further assert that identities are constructed within - not outside of - related discourse. Additionally, unity, for example, cannot be understood without fundamentally understanding concepts such as dissimilarity, uniqueness, inclusion, and exclusivity. For this reason, numerous scholars deem it essential, on behalf of all marginalized communities, to seek large-scale understanding through both historical and institutional contexts (Karp \& Helgø, 2009).

Indeed, history, economics, and climate must all be noted when considering the impact of identity on those who do not reflect or represent the 'norms' associated with the dominant culture. What is clear, according to Rutherford (1990), is that identity often only becomes an issue when it is "in crisis, and when something assumed to be fixed, coherent and stable is displaced by the experience of doubt and uncertainty. From this angle, the eagerness to talk about identity is symptomatic of the postmodern predicament of contemporary politics" (p. 43). As this relates to Black women collectively, the very mention of the word 'identity', because it is so non-traditional and ambiguous, tends to bring and heighten attention to other terms such as ‘identity crisis' and 'identity politics' (Rutherford, 1990).

Though the origins of intersectionality stretch back to sociopolitical movements of the 1960s and 1970s, Crenshaw (1989) is credited as the creator of the framework known as "intersectionality". Inspired by critical race theory (CRT) and Black feminism, this seminal frame aimed to explain the multiple factors that shape and perpetuate social inequities. 
According to Crenshaw $(1989,2005)$, intersectionality contextualizes and allows for a mapping of the ways in which race intersects with gender, ethnicity, nationality, language, and other key categories connected to social existence, (in)equalities, and (in)equities. The intersectional experience is complex, interminable, and overlapping, and these interrelated elements, over the course of a lifetime, serve to shape a person's life-course. Further, Crenshaw maintains that intersectionality is much more than a concept, notion, or buzzword; rather, it should be viewed as an avenue for change, beginning with a commitment to understanding the intricacies embedded within this lived experience.

Delgado and Stefancic (2012) state that "intersectionality means the examination of race, sex, class, national origin, and sexual orientation and how their combinations play out in various settings" (p. 51). Intersectionality holds that the roots of societal oppression, i.e. racism, sexism, homophobia, bigotry, etc., do not act independently of one another. Rather, as Crichlow (2015) contends, "these forms of oppression interrelate, are tied to each or are connected to each other creating a system or faces of oppression that reflects the 'intersection' of multiple forms of discrimination" (p. 188). It is the premise of intersectionality that people live layered identities, derived from social relations, history, and the operation of structured power. Moreover, intersectionality has now become part of policy initiatives, which have begun to recognize multiple intersecting inequalities (Anthias, 2013). In other words, "people are members of more than one category or social group and can simultaneously experience advantages and disadvantages related to those different social groups" (Richardson \& Loubier, 2008, p. 143).

\section{Race-Gender Intersectionality and Educational Leadership in the United States}

A growing number of scholars, including Eubanks, Brown, and Ybema (2012), have called for more studies about leadership identities, the impact of identity on individual 
differences, and how leaders progress from one identity stage to the next. Understanding the relationship between identity and leadership can help build the knowledge on individuals' development and future behaviors as leaders (Murphy, 1999). Exploring the contextual and intersecting variables surrounding identity is fundamental to explaining how leaders construct, develop, and execute their own identities (Eubanks et al., 2012). Moreover, according to Lord and Hall (2003), this exploration is by extension, fundamental to understanding effective leadership in this unique context.

In their critical review of race and ethnicity in the leadership literature, Ospina and Foldy (2009) determined that "insights about the leadership experience of people of color from contextrich research within education, communications and Black studies remain marginal in the field" (p. 876). Lord and Hall (2003) note that for Black women in and en route to positions in educational leadership, progress begins by recognizing that "leadership, identity, and social power are dynamically intertwined in a process that unfolds as group members interact and establish a status structure" (p. 48). The work entrenched in "building bridges from the margins" (Ospina \& Foldy, 2010, p. 292) involves the furtherance of research centered on the underlying roles that race and gender play in the development of non-archetypical leaders. Moving to increase diversity and expand representation in leadership requires a rethinking and reframing of intersectionality (Cho, Kim, \& Mor Barak, 2017; Nash, 2008) as it is applicable within the realm of leadership. Thus, this paper seeks to further conversations around the ways in which the intersecting elements, race and gender, are manifested within the context of US-based educational leadership.

In light of this, the current study examined the intersecting identities and vicarious experiences of four Black women, all purposefully selected because they hold some of the 
highest positions of leadership within the U.S. educational sphere. This work was framed by the following research question:

How have the racial and gender identities of Black women informed their educational and professional experiences in and on the path to leadership?

The information gathered here provides evidence for a greater understanding of how historic events have and continue to impact Black women's educational and leadership trajectories (Orbe, 2000; Ortiz, 1982). Moreover, understanding fundamental, chronological occurrences for Black women in educational leadership allows researchers to identify the factors connected to the current gap in representation in the effort to bring it to a close. For this reason, a careful examination of key historical hindrances (e.g., race, gender) that have impacted Black women in the academic arena is required. It is against this backdrop - confronting matters of ambiguity, complexity, context, and relevance - that this work, utilizing hermeneutic phenomenology as its methodology, was designed and implemented.

\section{The Current Study - A Phenomenological Design}

Taking these considerations into account, how can educational institutions in the U.S. mobilize to increase the number of Black women in leadership positions? Again, an understanding of the undertones relevant to all aspects of the organizational system - e.g., the continued problem of inequity in a post-President Barack Obama era - is essential (Bogotch, Schoorman, \& Reyes-Guerra, 2017; Lewandowsky, Ecker, \& Cook, 2017; Wise, 2009). Esposito and Finley (2009), in Barack Obama, racial progress, and the future of race relations in the United States, note the following:

A plethora of articles in the mainstream press describe Barack Obama's presidential election as a clear sign of racial progress. While this optimism is, in many respects, well 
justified, we suggest that many of these discussions, although typically well intended, point to a type of racial progress that operates within the prevailing racial status quo by conflating racial equity with color blindness, racial tolerance, and what Time Wise has recently termed "enlightened exceptionalism". 4 (p. 164)

The authors further argue that "framing racial progress in this manner obscures the structural character of US racism and reinforces the reality of White privilege" (Esposito \& Finley, 2009, p. 164). This acknowledgement, also highlighted by Daguerre (2011) in US social policy in the 21st Century: The difficulties of comprehensive social reform and Harris and Lieberman (2013) in Beyond discrimination: Racial inequality in a post-racist era, serves as a necessary first step toward developing large-scale, organizational-level strategies for lasting and impactful change.

Against this backdrop and considering the numerous distinct classifications of the phenomenology (Behnke et al., 2013; Moustakas, 1994; Van Manen, 1990), I embarked upon the hermeneutic phenomenological route (Heidegger, 1977, 1996). This perspective focuses on interpreting the structures of experience, and on how things are understood by people who live through these experiences and by those who study them (Byrne, 2001; Carpenter, 2007; Wojnar \& Swanson, 2007). Hermeneutic phenomenology is widely accepted as an engaging process where the orientation towards the phenomenon is the matter of central concern and its reporting rhetoric demands for a unique richness (Guba \& Lincoln, 1994; Kafle, 2011; Laverty, 2003).

\section{Selection of Participants}

Phenomenologists are interested in common features of a lived experience. Although "diverse samples might provide a broader range from which to distill the essence of the phenomenon, data from only a few individuals who have experienced the phenomenon — and

\footnotetext{
${ }^{4}$ Between Barack and a Hard Place: Racism and White Denial in the Age of Obama (Chapter 1). Retrieved January, 5, 2021, from https://www.washingtonpost.com/wp-srv/style/longterm/books/chap1/barackandahardplace.htm.
} 
who can provide a detailed account of their experience" (Starks \& Brown Trinidad, 2007, p.

1375) are deemed sufficient to uncover the core elements of a shared experience. According to Behnke et al. (2013), Moustakas (1994), Starks and Brown Trinidad (2007), Van Manen (1990) and other phenomenologists, typical sample sizes for phenomenological studies generally range from 1-10 people. In alignment with this, and consistent with saturation in qualitative research, four black women educational leaders were invited to participate in this study. These women hold the following titles: one district-level executive, two program directors, and one CEO of two Limited Liability Companies (LLCs) ${ }^{5}$, and each contributor has a minimum of 15 years of experience in her respective leadership role(s).

Maintaining respondent confidentiality while presenting thorough, comprehensive accounts of the lived experience remains a challenge for qualitative researchers. For this reason, and in the interest of protecting the identity of study contributors, their full names have been replaced with pseudonyms:

[Insert Table 1 about here]

Participants were selected because they all possess a plethora of experiences directly relevant to leadership in the educational realm. Additionally, they represent an array of locations within the United States (every contributor has senior-level leadership experience in at least two of each of the following regions: Northeast, Southeast, Northwest, and Southwest U.S.), a vast collection of knowledge, and a substantial educational leadership base spanning grades K-20 (primary through

\footnotetext{
${ }^{5}$ A Limited Liability Company (LLC) is a business structure allowed by state statute in the United States of America. See https://www.irs.gov/businesses/small-businesses-self-employed/limited-liability-companyllc\#: :text=A\%20Limited\%20Liability\%20Company\%20(LLC,an\%20LLC\%20are\%20called\%20members.
} 
graduate school). They were all personally contacted as exclusive members of this sample, and all four readily accepted the invitation to participate in this work.

\section{Data Collection and Analysis}

Data were primarily collected from face-to-face interviews (Guba \& Lincoln, 1982; Wolcott, 2005; Yin, 2003). Supplemental data were retrieved from artifacts and media-based sources of information (Schwandt, 2014). Three 60-minute rounds of interviews per person were deemed necessary to explore the breadth of each person's personal, educational, and professional challenges and successes throughout their journeys to their current roles as educational leaders. Each participant engaged in three sessions, resulting in a total of 12 interview hours (see Table 2):

[Insert Table 2 about here]

In addition to these 12 sessions, another 100 hours was spent transcribing and collating all interviews. The goal of employing a thorough, intensive 3-part interview process was to decrease the weaknesses of basing findings on any one individual occurrence, thereby strengthening the overall outcome of the study (Denzin \& Lincoln, 2008).

During the first round, participants were asked to share their background and general life experiences, highlighting the elements that set their lives apart from the very beginning. Round two included documentation of contributors' successes and barriers, and to the complexities specific to their leadership paths and roles. Round three served to bridge all connected, contextual factors including but not limited to: differing regional locations, varied perspectives, work-life balance, and participants' successful navigation of new terrain. In total, this series of 
conversations uncovered the plethora of 'then-and-now' decisions that were relevant to their journeys as Black women-turned-professionals-turned-leaders.

Pertinent, in this regard, were participants' unique successes and barriers as they journeyed on their respective paths into the educational leadership sphere. Contributors were asked, during the final round of interviews, to share the lessons and tools they learned and acquired along the way. In addition, they were called upon to share their own advice, strategies, and tools for other, burgeoning leaders - Black women in particular - seeking to carve their own niches towards top-tier leadership in education.

Possessing an "ontologically positive significance", the hermeneutic cycle signifies the role of the researcher in approaching the data analysis process not as a matter of a single, 'conscientious' decision, but as "the first, last, and constant task" (Gadamer, 2004, p. 269). The goals of hermeneutic research, in line with Heidegger thinking, are to enter the world of the person and interpret the meaning they assign to the experience at hand (McConnell-Henry, Chapman, \& Francis, 2009). In line with the mission of discovering and identifying all possible meanings, I combined interpretative phenomenological analysis (IPA) with the hermeneutic cycle. The utilization of this method involves "self-report data elicitation through interview associated with a sophisticated thematic analysis. The approach is idiographic and invariably linked to non-experimental research designs" (Smith \& Osborn, 2004, p. 229). The emergent themes, resulting from this IPA process, are highlighted in the sections below.

\section{Results}

Consistent with Smith and Osborn's (2004) interpretative phenomenological analysis (IPA) process, all essential steps were followed in recording and reporting the data, and this includes the matter of informed consent. Qualitative researchers face unique, and "often 
ambiguous, ethical dilemmas in disseminating this rich data. One such dilemma involves the conflict between conveying detailed, accurate accounts of the social world while simultaneously protecting the identities of the individuals who live in that particular social world" (Kaiser, 2009, pp. 1638-1639). Informed consent, then, particularly given the natural setting entrenched in qualitative research (Given, 2008; Silverman \& Marvasti, 2008) is a critical factor to be cognizant of in the accurate interpretation and dissemination of the collected data. As such, each participant received a hard copy of both the participant study invitation and the informed consent form, as signed consent was a prerequisite for study inclusion. This emphasis on the construction of the meaning of one's experience is vital to upholding the verity of the phenomenological process (Larkin, Eatough, \& Osborn, 2011). As a result of this intentionality, the following four themes emerged (see Figure 1):

[Insert Figure 1 about here]

\section{Emergent Themes}

Participants were called upon to share their knowledge about the unique challenges (successes and barriers) they face as Black women in the realm of educational leadership in the United States. Additionally, these women were asked to provide their insights regarding their own navigation of the leadership sphere. The emergent themes, resulting from our three-tiered conversations, are: (1) the importance of an established identity, (2) the complexity of equity as more than a singular construct, (3) navigating through the educational leadership sphere (i.e., context), and (4) balancing race, gender, and responsibility, all coalesced (i.e., intersected) within the realm of educational leadership. 
Establishing Their Identities. This theme, identity, emerged as participants spoke regularly of specific occurrences in which they identified as 'different'. The initial interview questions, in reference to contributors' personal and professional backgrounds, brought forth rich information about the pivotal factors that set their paths apart. Contributors expressed mixed sentiments regarding some of the introductory happenings that comprised their identities. Annie C., for example, had this to say about her early learning experiences in the classroom:

I would see just discrepancies on how White educators would interact with other White children versus how they would interact with me... But I had other, amazing experiences, where I had White teachers who were phenomenal and ...pivotal in my education, such as my 5 th grade math teacher. (Interview 1)

Monique M. spoke of the influence of her favorite teacher growing up, and when probed to elaborate further, she said,

I didn't think about it when I was a child, but I did really bond with her. I kept in contact with her until I went to college. But I think it's just one of those things where subconsciously you see somebody that is encouraging you to do it and I think that's the difference between when you have Black teachers or when you have role models.

\section{(Interview 1)}

Recalling her time as a high school student, Simone F. had this to say:

I lived in my own world. We would be sitting in math class. This is my 11 th grade year. And I had a...it was me and 3 other...people of color. One guy was Asian, but it was two guys and two girls. We all, we were the only people of color in that math class. I was usually one of very few...usually one of 3 Black people in my classes...my academic classes. (Interview 1) 
These testimonials reinforce the need to examine the lived experiences, i.e., the identity, roles, and perceptions of Black women in educational leadership (Grogan \& Shakeshaft, 2010). Consistent with Ospina and Foldy's (2009) critical review of race and ethnicity in the leadership literature is their determination that "insights about the leadership experience of people of color from context-rich research within education, communications and black studies remain marginal in the field" (p. 876). Relatedly, exploring the contextual and intersecting variables relevant to identity is fundamental to explaining how leaders construct, develop, and execute their own identities (Karp \& Helgø, 2008).

The Complexity of Equity. The theme, equity - and the complexity of incongruence emerged as everyone spoke of their accountability systems and the factors (good and bad) that impacted their decisions to become educational leaders in the first place. Participants were asked to talk about the complexities imbedded in their professional journeys; more specifically, contributors spoke to the uniqueness of oftentimes being the only 'representative' (i.e., woman, person of color, and/or both) in their spaces. Jacqueline G., for example, a district-level executive, relayed that she is:

...the only black person in the room ...Let's see; I counted yesterday, as a matter of fact, we had a meeting. I want to say, 12-15 directors, and none of them are black. So, I'm in the room with 20 others, from director on up to superintendent, there's probably 23 of us... and I'm the only African American in the room... and it just hurts me that I don't understand how we can't see that is an issue because it's not representative of our demographics. It's not even representative of our leadership at our school level, because when you go to the school level, we have African American Principals, we have several, 
a lot of African American Assistant Principals. We're pretty diverse at the school level, but we're not diverse when it goes beyond the school. (Interview 2)

Monique M., when asked about her decision to become an entrepreneurial educator, said:

How I ended up starting my nonprofit is just, when I was working at a school, just seeing kids who...didn't even think about STEM careers. ... and me having that background feeling heartbroken that they weren't, and trying to see what the barrier was, and most of it was just exposure. Like, the things that they were naming was careers that they were exposed to. (Interview 2)

The topics of 'equity' and 'support' brought with it a fluidity of responses regarding the people, accountability and systems - both supportive and unsupportive - that were central to them and their development into leaders. When asked about her transition from K-12 to higher educational leadership, Annie C. said:

You know, academia is very White. It's different. I just feel like there're a lot more barriers and restrictions...or less opportunity for Black women in academia than there are in K-12. I feel like if I wanted to be a building principal, or to go in at the district level...honestly, it's crossed my mind, just because I feel like it's...not a lot of opportunity or I haven't been getting the success that I want from different types of opportunities in higher education. I was like, well, maybe I should just go back in a district and start as an AP (Assistant Principal) and work my way up again, because I feel like that would be easier, if that's what I really wanted to do. It's not really what I want to do. I really want to teach at the higher education level. (Interview 2)

These glimpses of contributors' responses are in line with current scholarship, supporting the question of whether there is an implicit quota on women in leadership positions (Lennon, Spotts, 
\& Mitchell, 2013), as every participant spoke to the present domain of influence in their respective spheres. In this way, participants regularly noted the prevalence of inequities due to the longstanding single-track leadership archetype (Dezső, Ross, \& Uribe, 2016; Reagle \& Rhue, 2011), particularly within the realm of education.

Navigation in the Context of Educational Leadership. The theme, navigating through the educational leadership sphere, emerged as contributors spoke of varied experiences they encountered as they prepared for, entered, and continue to establish themselves as leaders in the context of education. In ongoing fashion, all spoke to the many encounters that they were minimally and/or ill-prepared for and the various times in which they were confronted with both their 'Blackness' and 'womanhood' (Alston, 2012; Howard-Hamilton, 2003). Annie C., in this same vein, said:

One of the challenges that I encountered in this role... The person in this position before me... She was not an educational leader. Her background and training was non-profit. She was an older White woman. ... and so, from my understanding, she kind of did what she was told, whereas, I came in with how I think this should be. I did what I wanted to do, honestly. ... and, I think, the other professors looked at me like, well that's not... I was not what they were used to. I was not what anybody was used to. I just wasn't. And so, I came up, and still to this day, come up against resistance. (Interview 3)

Simone F., in reference to one co-worker in particular, said:

I don't understand how you can hear everyone around you calling me Dr., but the first words out of your mouth are, Miss. Would you do that to a White man? If you hear everyone calling this White man Dr. 'so-and-so', do you say Mr.? I think not. You would quickly get his title, Doctor. Do you call Dr. X Mr. X? Uh, no, because you came and 
asked me, when can you have a meeting with Dr. X. So how, how is it that you know his title, but for some reason, I'm Miss Freeman? ... and I'm sure she's not doing that on purpose. I'm sure she's not doing that on purpose. (Interview 2)

According to Jacqueline G., it is important to:

...be aware that sometimes, there are going to be barriers in certain environments, but I truly believe that you can overcome those barriers if you learn to play the game... Because it, it really is like a game, in maneuvering your way through corporate America... Because even though I'm in the public sector, education is a big business. It is like a corporation too, because it has different levels of leadership just like corporations, and people make decisions about whether or not you're going to be allowed opportunities in those upper levels of management just like in corporations. (Interview 3)

Unique to their roles as Black women leaders, all respondents spoke to the varied successes and barriers - both advertent and inadvertent - they encountered on their leadership journeys. Finally, all contributors noted the many invaluable lessons they learned and how these experiences have and continue to inform their unique leadership paths.

Balancing Race, Gender, and Responsibility. Participants were asked to speak to their concurrent experiences as women, as Black women, and as educational leaders. The theme, balancing race, gender, and responsibility, arose as contributors talked about their unique and intersecting lives as Black women in senior-level educational leadership. In addition, they spoke of the successes and barriers they encountered and continue to encounter as leaders. Monique M., for example, spoke to this in her role as an "edupreneur", saying, "I think, you know, when it comes to women and women in STEM, um, it's hard to get us at the table and to share our 
experiences. Especially when you see those words diversity, inclusion" (Interview 3). When asked how their roles continue to inform their paths, Simone F. said, "I'm being prepared for a world that is not yet to come, but I'm living here, and I'm...pulling my hair out, saying, 'are we not attempting to strive towards that'? ...especially in a University setting... We are in a University setting, where you taught me this, and we can't live it out, we can't even live it out here? (Interview 3)

In this way, respondents' collective input was consistent with the growing body of scholarship focusing on "women's issues and the liberation of women from positions of disadvantage within various social, political, and economic systems" (Cox, 2015, p. 4). In education, this includes confronting the 'so how is that we have so many top-level positions that are held by men?' question (Jacqueline G., Interview 3). Regarding existing power relations, this affirms the importance of expanding the current discourse around race and gender, and the part these elements play in relation to extant social and organizational spheres (McCall, 2005; Verjee, 2012).

In similar fashion, study contributors provided ample information regarding their realities, perceptions, and strategies for navigating and leading within the realm of leadership. All spoke to 'answering the call' to lead, and all spoke to the numerous responsibilities and nuances involved for those who serve in spaces in which they are - and remain underrepresented. Annie C., speaking to her 'call to lead', said this about her current stance and outlook:

I could please a person for the moment but if that's not in alignment with my values...then that's not success to me....I don't want to be anybody's puppet, you know? Anybody's doormat... Because I've sacrificed too much, gone without too much, you 
know what I mean? To let people... I'm not doing that. ...you don't know what I had to go through to get here. (Interview 3).

Furthermore, in overwhelming fashion, all spoke to the price they paid - and continue to pay - to be educational leaders. Monique C., for example, spoke to the additional isolation she often feels - both personally and professionally - saying:

Most of my family is not STEM...actually, most of my support in my career path doesn't come from my family....me and my friend, the therapist, talk about it all the time. Just dysfunctional, Black behavior. Like, if you don't understand it, you can't support it. ... and so, that does have an area of isolation. ...you know, they're supportive when there's something they can brag on. But, [as for], the day to day, the weeds, you know... (Interview 2)

All participants recurrently acknowledged the great gains that women have made as active participants in society, in politics, in education, and in employment. Yet, they all equally pointed to the fact that the representation of women in positions of power and influence is - and remains - conspicuously less progressive (Harper, 2018; Theoharis, 2007).

\section{Bringing it all Together: Race + Gender + Educational Leadership}

The four aforementioned themes arose as a result of participants' reflections, insights, and totality of their experiences as leaders in education. Additionally, in response to the final interview question, 'What concluding remarks do you have for those seeking to more fully capture the experiences of Black women serving in and aspiring towards careers in educational leadership?', contributors responded by speaking to the role and responsibility of current leaders in education as activists. All women collectively defined activism as the persistent and direct work, on the part of the organizational leader, to ensure that everyone 'has a say'. Given this 
relevance to the tenets entrenched within socially just leadership, participants spoke to the need for educational leaders to be: (1) unafraid to confront issues that are complex and oftentimes ambiguous, and (2) cognizant of the many intricate, contextual factors that are specific to and within the educational sphere. At this juncture in her life, said Monique M., At least let me shape the conversation but I don't want to 'do the work'. So, I think sometimes when you see that as a Black woman, you're like, 'I don't want to teach anybody, anything. I don't want to be the spokesperson for that. I don't want to be in that conversation. Because you get exhausted... and then sometimes you feel like the people who are having that conversation, they don't care. They just want to say they've had the conversation. So, it gets really exhausting. Where sometimes you say anything and they... Nope, I don't want touch that with a $10 \mathrm{ft}$ pole. (Interview 3)

Connectedly, every participant spoke to the many nuances involved in navigating spaces in which they are only marginally represented (Hill et al., 2016; Yukl, 2009). The interminable grappling with identity that these women continue to experience speaks to the growing body of research suggesting that while women are highly suited for advanced leadership positions in every job sector (Sanchez-Hucles \& Davis, 2010), inequities remain prevalent in this sphere.

\section{Discussion}

The underscoring draw for Black women toward positions of leadership is the promise that educational institutions have resources and credentials, which provide global platforms for issues related to the Black woman experience. Historically, educational organizations are rooted in the unending mission to pursue knowledge, undergirded in the value of open-ended inquiry, and the cultivation of the merit-based professional. Yet the mission, while honorable, has not been historically actualized by all because of existent race, gender, and cultural biases toward 
Black women in educational leadership (Horsford \& Tillman, 2012). Although developments continue to be made, as highlighted by study participants, only very recently has significant advancement been made in what remains a historically and characteristically male-dominated space (Kulik \& Metz, 2015; O’Connor, 2010; Orelus, 2011).

Concomitant with the current study, numerous scholars, including Bogotch (2000), Mabokela and Madsen (2005), and Rawls (2009), mutually conclude that (1) leadership and diversity are continually interconnected; (2) U.S. schools are undergoing pressure to educate an increasingly diverse population of students, families, and communities; and (3) creating an inclusive school requires school leaders to vigorously respond (as opposed to simply reacting) to intergroup conflict among an increasingly diverse community/population. Study contributors' reflections align with growing scholarship specific to the complexities of educational leadership, and particularly, how school leaders who do not reflect the demographic of the majority perceive and negotiate their leadership roles and identities. This phenomenon, referred to as cultural incongruity (Mabokela \& Madsen, 2005), impacts the potential for marginalized leaders to create inclusive, productive, and progressive work environments in their respective spheres. The importance of an established identity (theme \#1) aligns with the growing calls for more action on the part of current educational leaders to advance this sphere by addressing the pertinent matters of equity, identity, and race-gender intersectionality while confronting the inequities that currently exist in this realm.

The work of numerous scholars, including Cho, Barrett, Solomon, Portelli, and Mujawamariya (2009), is also in line with this and other research regarding the complexity of equity and the race-gender dyad and the educational leadership sphere (theme \#2). Conjoined with participant responses, scholars, in ongoing fashion, assert the dire need for current 
educational leaders to serve as advocates. This includes but is not limited to: creating clearer collaborations and partnerships among stakeholders (including faculty, school boards, schools, communities), overtly working to increasing effective channels of communication and knowledge both within and between partnering organizations, and overtly validating the importance of conversations around equity, diversity and community-building.

This discourse, again, is especially relevant to and for Black women, considering the incongruence between their heightened levels of educational attainment as compared to their current statuses within the organizational leadership sphere. This is all the more significant within U.S.-based education, one in which women comprise the vast majority of the workforce. Undoubtedly, these incongruities are further exacerbated by environments in which "continued prioritization of the concerns of heterosexual White males is couched as Normality, Neutrality, Objectivity, and the Truth" (Wing, 2003, p. 1). In light of this, participants' accounts continue to reinforce the need for more research specific to the complex and intersecting experiences of Black women as they navigate through the educational leadership sphere (theme \#3).

\section{Conclusion}

Given that all organizations tend to be microcosms of contemporary life, understanding the undercurrents from every aspect of establishments is essential to developing positive and productive institutional cultures (Sack, 1986). Hence, investigating educational organizational leadership climate and its impact on advancement opportunities for Black women is necessary, for it leads to the development of fundamental awareness and macro-level understandings. Participants' accounts speak to the fact that increasing the number of qualified Black women in positions of educational administration and management is unquestionably an important component of this conversation. How, then, can educational institutions mobilize to increase the 
number of Black women in leadership positions? Theme \#4 - balancing race, gender, and responsibility - within the realm of educational leadership, seeks to shed light on this phenomenon.

Contributors' recollections emphasized the need to reframe and unpack the intersections of race and gender in U.S.-based education and investigate how these elements directly impact the representation of underrepresented people - Black women in this context - in the realm of leadership. As they continue to balance race, gender, and their leadership responsibilities, participants highlighted the need for more advocacy on the part of current leaders, through the establishment of actionable strategies that are inclusive, fair, and socially just (Moorosi, Fuller, \& Reilly, 2018; Ngwainmbi, 2004; Pratt-Clarke \& Maes, 2017). Each study member specifically spoke to the need for current stakeholders to overtly supporting and promoting equity, fairness, and social justice through professional development and other in-house supports (Marshall, Young, \& Moll, 2006; Newcomb \& Mansfield, 2014). Activism, as a recurring thread, remains applicable within the leadership sphere, and participants stressed the fact that activism is persistently and directly entrenched within the tenets of social justice leadership (Black \& Murtadha, 2007; Bryson \& Crosby, 1992; Goldfarb \& Grinberg, 2001). Further, all participants identified the need for more mentors, safe spaces, and pathways to leadership for Black women in education, especially considering that Black women represent a growing pool of educators in the U.S., primed for positions of leadership. These and other related experiences highlight the complex nuances involved in the navigation of their leadership paths, including the successes and barriers that are unique and specific to them as Black women (Rosette et al., 2016).

My purpose, in this respect, is to further the work involved in deliberately and explicitly promoting equitability and justice in this capacity (Pignatelli, 1993). Although black women are 
represented in education, they are - and remain - underrepresented in leadership (Evans, 2008; Selsky, 1991; Shakeshaft, 1989). By examining, then, the vicarious experiences of these four women, researchers are encouraged to gain a more productive understanding and appreciation for diversification in educational leadership representation. Taken together, this study marks my effort to connect with relevant stakeholders to further the knowledge, research, conversations, and actionable strategies specific to the advancement of Black women in and en route to seniorlevel educational leadership positions. The call to reduce the noted educational leadership gaps in this regard is undoubtedly a step in the right direction. 


\section{References}

Allan, E. J. (2003). Constructing women's status: Policy discourses of university women's commission policy reports. Harvard Educational Review, 73(1), 44-72.

Alston, J. A. (2012). Standing on the promises: A new generation of Black women scholars in educational leadership and beyond. International Journal of Qualitative Studies in Education, 25(1), 127-129.

Anderson, G. L. (2009). Advocacy leadership: Toward a post-reform agenda in education. Routledge.

Anthias, F. (2013). Intersectional what? Social divisions, intersectionality and levels of analysis. Ethnicities, 13(1), 3-19.

Behnke, E. A., Carr, D., Evans, J. C., Huertas-Jourda, J., Kockelmans, J. J., Mckenna, W., ... \& Zaner, R. M. (2013). Encyclopedia of Phenomenology (Vol. 18). Springer Science \& Business Media.

Bell, E. L., \& Nkomo, S. M. (2001). Our separate ways: Black and White women forging paths in corporate America. Unpublished book manuscript.

Black, W. R., \& Murtadha, K. (2007). Toward a signature pedagogy in educational leadership preparation and program assessment. Journal of Research on Leadership Education, 2(1), $1-29$.

Bogotch, I., Schoorman, D., \& Reyes-Guerra, D. (2017). Forging the needed dialogue between educational leadership and curriculum inquiry: Placing social justice, democracy, and multicultural perspectives into practice. In Bridging Educational Leadership, Curriculum Theory and Didaktik (pp. 283-307). Springer, Cham. 
Bogotch, I. E. (2000). Educational leadership and social justice: Theory into practice. Journal of School Leadership, 12(2), 138-156.

Bryson, J. M., \& Crosby, B. C. (1992). Leadership for the common good: Tackling public problems in a shared-power world. Jossey-Bass.

Byrne, M. M. (2001). Understanding life experiences through a phenomenological approach to research. AORN journal, 73(4), 830-832.

Betters-Reed, B. L., \& Moore, L. L. (1995). Shifting the management development paradigm for women. Journal of Management Development, 14(2), 24-38.

Carpenter, D. R. (2007). Phenomenology as method. In H. J. Streubert \& D. R. Carpenter (Eds.), Qualitative research in nursing: Advancing the humanistic imperative (pp. 75-99). Philadelphia, PA: Lippincott.

Cho, C., Barrett, S.E., Solomon, R.P., Portelli, J.P., \& Mujawamariya, D. (2009). Mentorship and induction: Negotiating a collaborative enterprise or apprenticing for status quo maintenance? Brock Education, 8(2), 114-130.

Cho, S., Kim, A., \& Mor Barak, M. E. (2017). Does diversity matter? Exploring workforce diversity, diversity management, and organizational performance in social enterprises. Asian Social Work and Policy Review, 11(3), 193-204.

Cox, K. (2015). Feminist theory in sociology. Research Starters: Sociology.

Crenshaw, K. (1989). Demarginalizing the intersection of race and sex: A Black feminist critique of antidiscrimination doctrine, feminist theory and antiracist politics. University of Chicago Legal Forum, 139.

Crenshaw, K. (2005). Mapping the margins: Intersectionality, identity politics, and violence against women of color (1994). 
Crichlow, W. (2015). Critical race theory: A strategy for framing discussions around social justice and democratic education. Higher Education in Transformation Conference, Dublin, Ireland, 2015, 187-201.

Daguerre, A. (2011). US social policy in the 21st century: The difficulties of comprehensive social reform. Social Policy \& Administration, 45(4), 389-407.

Davidson, M. J., \& Burke, R. J. (Eds.). (2000). Women in management: Current research issues (Vol. 2). Sage.

Delgado, R., \& Stefancic, J. (2012). Critical race theory: An introduction. New York: NYU Press.

Denzin, N. K., \& Lincoln, Y. S. (2008). The landscape of qualitative research (Vol. 1). Sage.

DeWitt, P. M. (2016). Collaborative leadership: Six influences that matter most. Corwin Press.

Dezső, C. L., Ross, D. G., \& Uribe, J. (2016). Is there an implicit quota on women in top management? A large-sample statistical analysis. Strategic Management Journal, 37(1), 98-115.

Eagly, A. H., \& Carli, L. L. (2007). Women and the labyrinth of leadership. Harvard Business Review, 85(9).

Eagly, A. H., Eagly, L. L. C. A. H., \& Carli, L. L. (2007). Through the labyrinth: The truth about how women become leaders. Harvard Business Press.

Esposito, L., \& Finley, L. L. (2009). Barack Obama, racial progress, and the future of race relations in the United States. Western Journal of Black Studies, 33(3).

Eubanks, D. L., Brown, A. D., \& Ybema, S. (2012). Leadership, identity, and ethics. Journal of Business Ethics, 107(1), 1-3. 
Evans, S. Y. (2008). Black women in the ivory tower, 1850-1954: An intellectual history. Gainesville: University Press of Florida. Retrieved September 5, 2018, from Project MUSE database.

Gadamer, H. G. (2004). Truth and method, translation revised by Joel Weinsheimer and Donald G. Marshall, London \& New York: Continuum.

Given, L. M. (Ed.). (2008). The Sage encyclopedia of qualitative research methods. Sage Publications.

Goldfarb, K. P., \& Grinberg, J. (2001). Leadership for social justice: Authentic participation in the case of a community center in Caracas, Venezuela. Journal of School Leadership, 12, 157-73.

Grogan, M., \& Shakeshaft, C. (2010). Women and educational leadership (Vol. 10). John Wiley \& Sons.

Guba, E. G., \& Lincoln, Y. S. (1994). Competing paradigms in qualitative research. Handbook of Qualitative Research, 2(163-194), 105-117.

Guba, E. G., \& Lincoln, Y. S. (1982). Epistemological and methodological bases of naturalistic inquiry. Educational Technology Research and Development, 30(4), 233-252.

Gupton, S. L. (2009). Women in educational leadership in the US: Reflections of a 50-year veteran. In Forum on Public Policy Online (Vol. 2009, No. 2). Oxford Round Table. 406 West Florida Avenue, Urbana, IL 61801.

Hall, S., \& Du Gay, P. (Eds.). (1996). Questions of cultural identity: SAGE Publications. Sage. Harper, J. (2018). Webinar recording: Year in review: Why diversity and inclusion matter. Catalyst. 
Harris, F. C., \& Lieberman, R. C. (Eds.). (2013). Beyond Discrimination: racial inequality in a post-racist era. Russell Sage Foundation.

Heidegger, M. (1996). Being and time: A translation of Sein and Zeit (J. Stambaugh, Trans.).

Albany, New York: State University of New York Press.

Heidegger, M. (1977). The question concerning technology and other essays (W. Lovitt, Trans.). New York: Harper.

Hill, C., Miller, K., Benson, K., \& Handley, G. (2016). Barriers and bias: The status of women in leadership. American Association of University Women.

Hofstede, G. (2011). Dimensionalizing cultures: The Hofstede model in context. Online readings in psychology and culture, 2(1), 8.

Horsford, S. D., \& Tillman, L. C. (2012). Inventing herself: Examining the intersectional identities and educational leadership of Black women in the USA. International Journal of Qualitative Studies in Education, 25(1), 1-9.

Howard-Hamilton, M. F. (2003). Theoretical frameworks for African American women. New Directions for Student Services, 104, 19-27.

Hussar, B., Zhang, J., Hein, S., Wang, K., Roberts, A., Cui, J., ... \& Dilig, R. (2020). The Condition of Education 2020. NCES 2020-144. National Center for Education Statistics.

Kafle, N. P. (2011). Hermeneutic phenomenological research method simplified. Bodhi: An Interdisciplinary Journal, 5(1), 181-200.

Kaiser, K. (2009). Protecting respondent confidentiality in qualitative research. Qualitative Health Research, 19(11), 1632-1641. 
Karp, T., \& Helgø, T. I. (2009). Leadership as identity construction: The act of leading people in organisations: A perspective from the complexity sciences. Journal of Management Development, 28(10), 880-896.

Kellerman, B., Rhode, D. L., \& O’Connor, S. D. (2007). Women and leadership: The state of play and strategies for change (Vol. 141). Jossey-Bass.

Kulik, C. T., \& Metz, I. (2015). Women at the top: Will more women in senior roles impact organizational effectiveness?

Larkin, M., Eatough, V., \& Osborn, M. (2011). Interpretative phenomenological analysis and embodied, active, situated cognition. Theory \& Psychology, 21(3), 318-337.

Laverty, S. M. (2003). Hermeneutic phenomenology and phenomenology: A comparison of historical and methodological considerations. International Journal of Qualitative Methods, 2(3), 21-35.

Lennon, T., Spotts, D., \& Mitchell, M. (2013). Benchmarking women's leadership in the United States. Colorado Women's College at the University of Denver.

Lewandowsky, S., Ecker, U. K., \& Cook, J. (2017). Beyond misinformation: Understanding and coping with the "post-truth" era. Journal of Applied Research in Memory and Cognition, 6(4), 353-369.

Lord, R., \& Hall, R. (2003). Identity, leadership categorization, and leadership schema. Leadership and power: Identity processes in groups and organizations, 48, 64 .

Mabokela, R. O., \& Madsen, J. A. (2005). 'Color-blind' and 'color-conscious' leadership: A case study of desegregated suburban schools in the USA. International Journal of Leadership in Education, 8(3), 187-206. 
Marshall, C., Young, M., \& Moll, L. U. I. S. (2006). The wider societal challenge: An afterword. Leadership for social justice: Making revolutions in education, 307-317.

McCall, L. (2005). The complexity of intersectionality. Signs: Journal of Women in Culture and Society, 30(3), 1771-1800.

McConnell-Henry, T., Chapman, Y., \& Francis, K. (2009). Unpacking heideggerian phenomenology. Southern Online Journal of Nursing Research, 9(1), 1-11.

McFarland, J., Hussar, B., Zhang, J., Wang, X., Wang, K., Hein, S., ... \& Barmer, A. (2019). The Condition of Education 2019. NCES 2019-144. National Center for Education Statistics.

Moorosi, P., Fuller, K., \& Reilly, E. (2018). Leadership and intersectionality: Constructions of successful leadership among Black women school principals in three different contexts. Management in Education, 152-159.

Moustakas, C. E. (1994). Phenomenological research methods. Thousand Oaks, CA: Sage.

Murphy, J. (1999). The quest for a center: Notes on the state of the profession of educational leadership, 1-104.

Nash, J. C. (2008). Re-thinking intersectionality. Feminist review, 89(1), 1-15.

Newcomb, W. S., \& Mansfield, K. C. (Eds.). (2014). Women interrupting, disrupting, and revolutionizing educational policy and practice. IAP.

Ngwainmbi, J. M. (2004). Feminism, feminist scholarship, and social integration of women: The struggle for African-American women. Journal of International Women's Studies, 5(5), 93-104.

O’Connor, K. (2010). Gender and women's leadership: A reference handbook (Vol. 1). Sage. 
Orbe, M. P. (2000). Centralizing diverse racial/ethnic voices in scholarly research: The value of phenomenological inquiry. International Journal of Intercultural Relations, 24(5), 603621.

Orelus, P. W. (2011). Rethinking race, class, language, and gender: A dialogue with Noam Chomsky and other leading scholars. Rowman \& Littlefield Publishers.

Ortiz, F. I. (1982). Career patterns in education: Women, men, and minorities in public school administration. New York: Praeger.

Ospina, S., \& Foldy, E. (2009). A critical review of race and ethnicity in the leadership literature: Surfacing context, power and the collective dimensions of leadership. The Leadership Quarterly, 20(6), 876-896.

Ospina, S., \& Foldy, E. (2010). Building bridges from the margins: The work of leadership in social change organizations. The Leadership Quarterly, 21(2), 292-307. Patton, M. Q. (1999). Enhancing the quality and credibility of qualitative analysis. Health Services Research, 34(5 Pt 2), 1189-1208.

Parker, L., \& Villalpando, O. (2007). A race(cialized) perspective on education leadership: Critical race theory in educational administration. Educational Administration Quarterly, 43(5), 519-524.

Patton, M. Q. (2002). Two decades of developments in qualitative inquiry: A personal, experiential perspective. Qualitative Social Work, 1(3), 261-283.

Pignatelli, F. (1993). Toward a postprogressive theory of education. Educational Foundations, 7(3), 7-26.

Pratt-Clarke, M. \& Maes, J. (2017). Journeys of social justice: Women of color presidents in the academy. Peter Lang Inc., International Academic Publishers. 
Prime, J. L., Carter, N. M., \& Welbourne, T. M. (2009). Women "take care," men "take charge": Managers' stereotypic perceptions of women and men leaders. The Psychologist-Manager Journal, 12(1), 25.

Rawls, J. (2009). A theory of justice. Harvard University Press.

Reagle, J., \& Rhue, L. (2011). Gender bias in Wikipedia and Britannica. International Journal of Communication, 5, 21.

Rhode, D. L. (2017). Women and leadership. Oxford University Press.

Richardson, A., \& Loubier, C. (2008). Intersectionality and leadership. International Journal of Leadership Studies, 3(2), 142-161.

Rosette, A. S., Koval, C. Z., Ma, A., \& Livingston, R. (2016). Race matters for women leaders: Intersectional effects on agentic deficiencies and penalties. The Leadership Quarterly, 27(3), 429-445.

Rutherford, J. (1990). Identity: community, culture, difference. Lawrence \& Wishart.

Sanchez-Hucles, J. V., \& Davis, D. D. (2010). Women and women of color in leadership: Complexity, identity, and intersectionality. American Psychologist, 65(3), 171.

Sawyer, K., Salter, N., \& Thoroughgood, C. (2013). Studying individual identities is good, but examining intersectionality is better. Industrial and Organizational Psychology, 6(1), 8084.

Schwandt, T. A. (2014). The Sage dictionary of qualitative inquiry. Sage Publications.

Selsky, J. W. (1991). Lessons in community development: An activist approach to stimulating interorganizational collaboration. The Journal of Applied Behavioral Science, 27(1), 91115. 
Shakeshaft, C. (1989). Women in educational administration. Sage Publications, Corwin Press, 2455 Teller Road, Newbury Park, CA 91320.

Silverman, D., \& Marvasti, A. (2008). Doing qualitative research: A comprehensive guide. Sage.

Smith, J. A., \& Osborn, M. (2004). Interpretative phenomenological analysis (pp. 229-254). The British Psychological Society and Blackwell Publishing Ltd.

Starks, H., \& Brown Trinidad, S. (2007). Choose your method: A comparison of phenomenology, discourse analysis, and grounded theory. Qualitative Health Research, 17(10), 1372-1380.

Suri, H. (2011). Purposeful sampling in qualitative research synthesis. Qualitative Research Journal, 11(2), 63-75.

Theoharis, G. (2007). Social justice educational leaders and resistance: Toward a theory of social justice leadership. Educational Administration Quarterly, 43(2), 221-258.

US Department of Education. (2016). The state of racial diversity in the educator workforce. https://www2.ed.gov/rschstat/eval/highered/racial-diversity/state-racial-diversityworkforce.pdf.

Van Manen, M. (1990). Researching lived experiences. State University of New York Press, Albany.

Verjee, B. (2012). Critical race feminism: A transformative vision for service-learning engagement. Journal of Community Engagement and Scholarship, 5(1), 57-69.

Wing, A. K. (Ed.). (2003). Critical race feminism: A reader. ( $2^{\text {nd }}$ Ed). NYU Press.

Wise, T. (2009). Between Barack and a hard place: Racism and white denial in the age of Obama. City Lights Books. 
Wojnar, D. M., \& Swanson, K. M. (2007). Phenomenology: An exploration. Journal of Holistic Nursing, 25(3), 172-180.

Wolcott, H. F. (2005). The art of fieldwork ( $2^{\text {nd }}$ ed.). Walnut Creek, CA: AltaMira Press.

Yin, R. K. (2003). Case study research, design and methods (3rd ed.). Thousand Oaks, CA: Sage.

Yukl, G. (2009). Leading organizational learning: Reflections on theory and research. The Leadership Quarterly, 20(1), 49-53. 